\title{
The Principles of Surgical Practice: Sushruta Samhita and its Importance to Present Day Surgery
}

\author{
Abhinav Kumar ${ }^{1}$, and B Nirmal Kumar ${ }^{2, *}$ \\ ${ }^{1}$ University College London, United Kingdom \\ ${ }^{2}$ Wrightington, Wigan and Leigh NHS Foundation Trust, Wigan, United Kingdom
}

*Corresponding author: B Nirmal Kumar, Wrightington, Wigan and Leigh NHS Foundation Trust, Wigan, United Kingdom, E-mail: nirmalkumar@doctors.org.uk

Received: 16 Jan, 2020 | Accepted: 27 Jan, 2020 | Published: 31 Jan, 2020

Citation: Kumar A, Kumar BN (2020) The Principles of Surgical Practice: Sushruta Samhita and its Importance to Present Day Surgery. J Surg Open Access 6(2): dx.doi.org/10.16966/2470-0991.207

Copyright: (c) 2020 Kumar A, et al. This is an open-access article distributed under the terms of the Creative Commons Attribution License, which permits unrestricted use, distribution, and reproduction in any medium, provided the original author and source are credited.

\section{Abstract}

The Sushruta Samhita is one of the oldest texts dedicated to surgery with various techniques and principles mentioned. It is most famous for describing the basis of modern Rhinoplasty and earned the author, Aacharya Sushruta, the title of 'the Father of Plastic Surgery'. Whilst the text was written around $600 \mathrm{BC}$ its relevance to the modern day is evident, with many basic principles established that are still used in practice today. In prehistoric times surgery was often a primitive and unscientific undertaking, and manuscripts like this were essential for the growth of surgery as a defined speciality alongside medicine. It's importance to the modern day and its impact on the surgical field is assessed in the article.

\section{Introduction}

Surgery has existed in its most primitive form since prehistoric times, with evidence of interventions such as trepanation, setting of bones and bloodletting being used as common treatments for certain ailments. It was considered a dangerous undertaking and with limited forms of anaesthesia the surgical procedures would be quick and usually only surface ailments could be treated. Around $600 \mathrm{BC}$ a physician, philosopher and teacher in ancient India called Aacharya Sushruta was one of the first physicians to write and record various medical procedures and is known as the Father of Plastic Surgery. He invented and developed many surgical procedures including the basis of modern rhinoplasty. His written work the Sushruta Samhita is one of the oldest texts dedicated to surgical techniques, and surrounding medical disciplines such as midwifery and many others. The text, divided into six sections, describes in detail the various branches of surgery which includes military medicine, medical ethics, teaching methods, dissection of human body, dissection practices and operative surgical exercises on vegetables, and other models like fabric. It is highly regarded as one of the trilogy of Ayurvedic Medicine; the other two being Charaka Samhita which preceded it and the Astanga Hridaya which followed it. Many translations of the Sushruta Samhita were made for different cultures over the following centuries with passages from the text stimulating the growth of modern plastic surgery in Europe as recently as the $19^{\text {th }}$ century. Although the original manuscript of the Sushruta Samhita has not survived to the modern day the copies and revisions still exist in many forms around the world. Its impact on the evolution of surgical practice worldwide cannot be understated, but it's relevance to modern medicine and the future surgical developments may be diminished as innovations in robotics and artificial intelligence become more prevalent (Figures 1 and 2).

\section{Surgery in the Sushruta Samhita}

The Sushruta Samhita is one of the oldest texts dealing with surgery, and whilst plastic surgery is often mistakenly considered to be a new speciality, Sushruta was most likely the first surgeon to perform plastic surgery. The most famous surgical procedure detailed in the Sushruta Samhita that still holds relevance to this day is rhinoplasty, the operation which earned Sushruta the title of the originator of plastic surgery. Nasal reconstruction is a complex facial reconstruction procedure and is a major aesthetic focus on the face. A common form of criminal or military punishment in Ancient India was the amputation of the nose, earlobes or genitalia, creating a demand for reconstructive surgery [1]. As printing wasn't possible at this time in ancient India the free-graft rhinoplasty is described in detailed verse form for nasal reconstruction, and to this day is still sometimes referred to as the Indian flap [2] (although the Indian flap rhinoplasty using the skin from the adjacent forehead is a modification of the classical cheek-flap rhinoplasty detailed by Sushruta). It is the gold standard for nasal soft tissue reconstruction and gives the surgeon a large amount of tissue for reconstruction of a defect [3]. Even though the surgery was revolutionary for its time the translation and spread of that knowledge took quite some time to reach Europe. The Indian Rhinoplasty was eventually published in the October 1794 issue of the Gentleman's Magazine of London after British surgeons working for the East India Company viewed the operation being performed by an 
Indian surgeon around the period of the Mysore War in 1792. The first successful rhinoplasty operation in Europe using the Indian technique was performed by the British surgeon Carpue on $23^{\text {rd }}$ October 1814 which lasted 37 minutes. Following more successful operations being performed and their subsequent publications the usefulness of the Indian technique would then be recognized by British and European surgeons culminating in at least 152 rhinoplasties being performed by 1897. The Rhinoplasties called the 'Indian Nose' gained huge interest in Europe and the United States and popularized the technique that after refinement became an established procedure worldwide [2]. The translation and dissemination of Sushruta's teaching is evident and led prominent medical historians such as Erwin Ackernecht to recognise that the plastic surgery practiced in Europe was a descendant of the classical Indian surgery [4].

The Sushruta Samhita acts as a training manual and educative text for surgery, and enabled a move away from the more primitive forms of surgery practiced beforehand. Many procedures and methods of surgery were described and in some way acts as a basic manual from which surgery in the modern day has grown from. Sushruta's procedures in the field of ophthalmology is one such area in which modern day surgery has a direct root, with around 18 chapters dedicated to 76 different diseases of the eye and the various operations to treat them. Due to the complex nature of cataract surgery many historians find it hard to believe that a form of cataract surgery could have happened in the 6th century BC, whilst others argue that Sushruta was the first surgeon to successfully remove cataracts. Like the freegraft rhinoplasty Sushruta painstakingly details the process of extracapsular extraction in written verse for the treatment of cataracts. One technique that is described that is a direct precursor to modern cataract surgery is the depression method of couching by the anterior root and therefore dislodging the lens and removing the opacity. With Sushruta being a physician in a region with close proximity to the equator a lot of ocular conditions from sensitivity to ultraviolet light would be present, meaning conditions such as cataracts are a pressing problem in that region. Another ophthalmologic condition detailed in the Sushruta Samhita was the stages of Pterygium. A step by step guide to treating the condition is highlighted in the text starting with topical drops and salves and then moving to surgical excision of the inflamed pterygium [5]. Similar to the rhinoplasty procedure the techniques have undergone refinement with more sophisticated tools and medicinals being used, but the basis of the procedure is related to what is done in current surgical practice. An excerpt from the text can highlight this; "Perioperatively the eye is irritated with saindhava salt and soaked with a warm compress. The patient faces the surgeon while sitting and is asked to look at the interior corner of his affected eye. The lids are held wide apart and the pterygium is secured with a hook and held with a threaded needle. This is then excised at its base with the mandalagra instrument. The root of the pterygium should be pushed asunder from the cornea and then removed. Postoperatively the area is rubbed with a compound made up of various salts, fomented and bandaged for three days. This will recur if not properly excised." [6].

Alongside the treatment of conditions such as Trichiasis which was a common procedure and detailed in Sushruta's text, the ocular conditions therapy used today certainly can be traced to innovations mentioned in the Sushruta Samhita, even if later translations of the text and developing medical knowledge has refined the procedures to the modern day.

Whilst Sushruta's developments of surgical techniques are well known his refining of surgical instruments allowed for more sophisticated forms of surgery to take place. His text describes the use

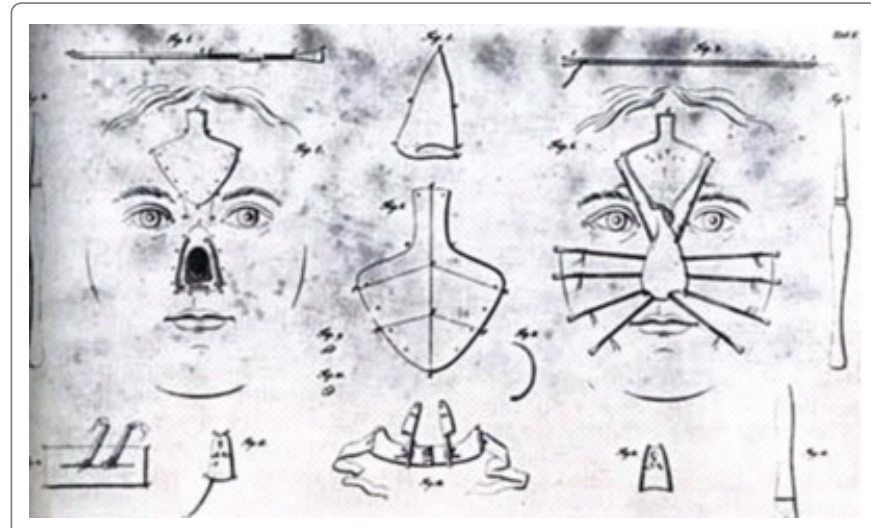

Figure 1: 'Indian Flap' for nasal reconstruction.

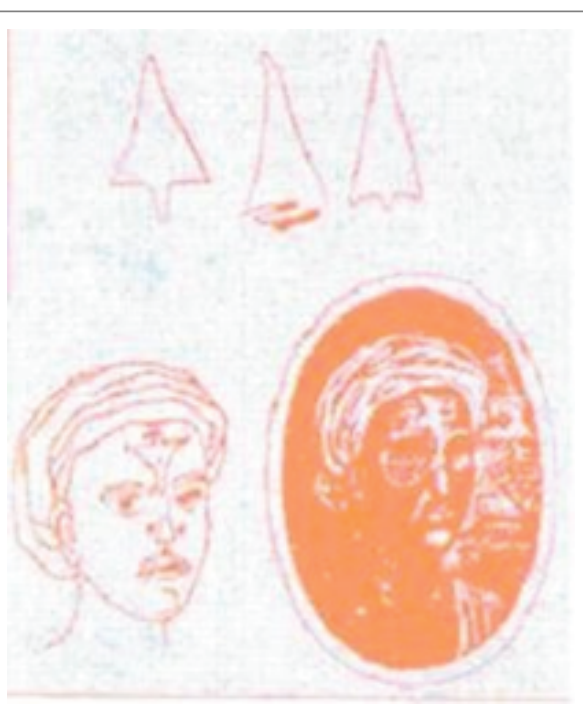

Figure 2: Reconstruction of the nose by forehead Rhinoplasty.

of 20 sharp instruments that "should have an edge so fine that it should divide the hairs on the skin," and 101 blunt instruments [5] (Figure 3).

His work on surgical instruments is not seen in any other medical text of that time period and leads to the argument that he was one of the first surgeons to classify and describe surgical instruments and their use in diagnosis and treatment. Interestingly his contributions to endoscopes (such as rectal, aural, nasal, and vaginal specula) are not well known yet his text provides evidence of examination and treatment of diseased spots of these external orifices. The instruments have a hollow interior with an opening at one or both ends which allows for inspection but also removal of foreign bodies [7]. His work and development of surgical instruments and endoscopes allows for a more precise surgical procedure to take place and has set a template for modern surgery in which skilled technique and the correct equipment are essential aspects for a surgeon to require.

\section{The Basic Principles of Surgery from Sushruta Samhita}

Although surgery and mainly rhinoplasty will be the focal point of the Sushruta Samhita when looking at its impact on today's world of surgery, there were other important aspects of the text that established many basic surgical principles that are still relevant today. Sushruta classified surgery according to seven disciplines, Chhedya (excision), 


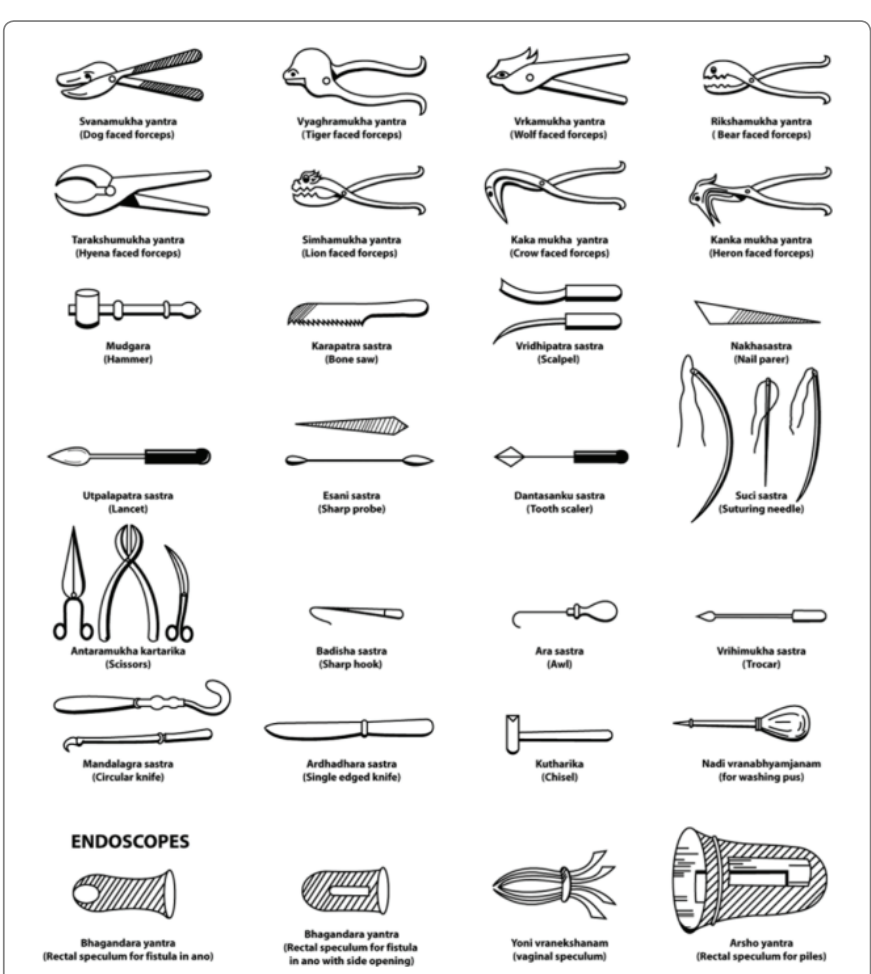

Figure 3: Surgical instruments from the Sushruta Samhita.

Lekhya (scarification), Vedhya (puncturing), Eshya (exploration), Aharya (extraction), Visravya (evacuation), and Sivya (suturing) [8]. Ultimately the Sushruta Samhita is a text that is used for educating students on the basics of surgery in a broad range of diseases, and the disciplines mentioned earlier are quite broad but ultimately still hold true to surgery even to this day. As a teacher he taught the importance of combining theory and practical knowledge for treatment which lead the Sushruta Samhita to contain practical exercises to allow students to artificially practice surgery. His experimental models for students to practice skills such as suturing and puncturing included carcasses and even vegetables [9]. For current surgical students we have augmented or virtual reality in which surgeons can practice their skills and attain a level of competency before undertaking a procedure on a patient (in which the consequences are much higher). So therefore even at a basic level the concept of surgical training and the acquisition of skills for surgical students was as evident to Sushruta as it is to our understanding of learning today. Sushruta emphasised the learning of anatomy in his teachings, and although this would seem obvious to us in the present day that an understanding of anatomy is essential for safe surgery, there was a stigma in ancient and medieval cultures to explore the anatomy of a corpse (it was often seen as unholy) which means dissections of cadavers would be impossible. Sushruta as a practicing physician understood the importance of surgery and defied the belief of prehistoric and medieval medicine that surgery was a last resort. As we now understand surgery can be the most effective treatment in alleviating symptoms in certain conditions, and this understanding is groundbreaking compared to the relative reluctance of using surgery that was present at the time.

Sushruta states; "Surgery has the superior advantage of producing instantaneous effects by means of surgical instruments and appliances. Hence, it is the highest in value of all the medical tantras. It is eternal and a source of infinite piety, imports fame and opens the gates of

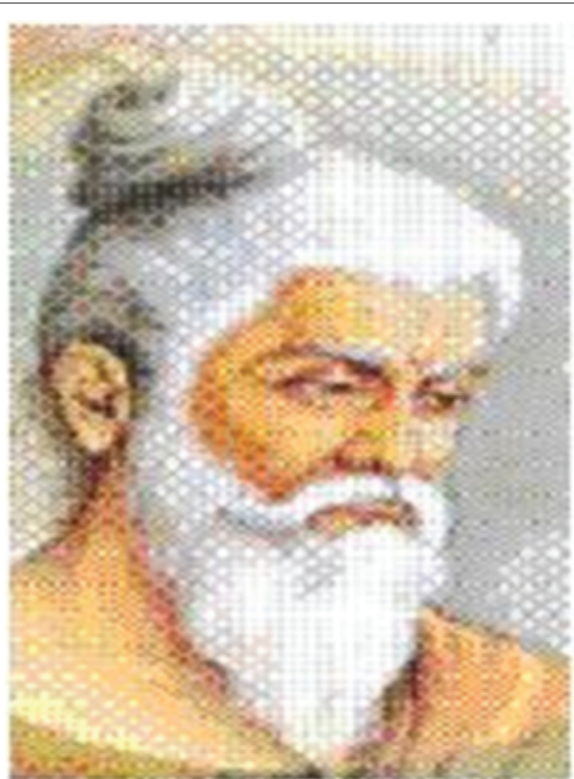

Figure 4: Sushruta (600 B.C).

Heaven to its votaries. It prolongs the duration of human existence on earth and helps men in successfully fulfilling their missions and earning a decent competence in life" [4]

In modern healthcare the surgical and medical fields are not practiced in isolation but are instead used together to treat patients. In the Sushruta Samhita we see an emphasis on providing holistic care to patients in terms of both physical and mental well-being, and also maintenance of other bodily functions or 'humors'. The text provides details on preoperative and postoperative care, diet, techniques, indications and contraindications, and complications [10]. This form of care is practiced to this day and is a requirement in all good clinical scenarios for treating patients. Our modern day practice of physicians taking a medical history and deciding upon medical, surgical or alternative treatments based on the patient history is considered a more recent innovation in the medical field [11], but elements of it seemed to be discussed as early as Sushruta's time. Sushruta's belief that knowledge of both surgery and medicine as being essential to make a good doctor is enormously important, and as he claims that without both a doctor "is like a bird with only one wing" [10]. The overall demeanour and character of a doctor is set out by Sushruta, "a physician who has set out on this path should have witnessed operations. He must be licensed by the king. He should be clean and keep his nails and hair short. He should be cheerful, well-spoken and honest" [4]. Whilst this reference is outdated for the present day the overall emphasis on good interpersonal skills and a defined doctorpatient relationship is one that very much applies to modern medical practice.

The use of anaesthesia in the Sushruta Samhita is essential in allowing the growth of surgical techniques. With the adequate control of pain, surgeries could become longer and more complex and are no longer restricted to simple amputations and external growth removals. The Sushruta Samhita advocates the use of wine with incense of cannabis for anaesthesia [9], and although this method of anaesthesia is primitive it set a benchmark allowing the combination of adequate pain control and more intricate procedures to be the accepted practice in surgery (Figure 4). 


\section{Conclusion}

The Sushruta Samhita is a text whose authenticity is questioned a lot, due to its repeated translations and revisions, yet it is still cited as one of the first and most important pieces of surgical history. The text acts as a bible of surgical practice which establishes basic techniques from suturing to hygiene that is essential for good medical practice. The field of plastic surgery has greatly benefitted from the teachings in the Sushruta Samhita and is exemplified by the rhinoplasty procedure which is the most well known area from the text. Although it is a historical document in which most of the procedures would not be practiced in the current climate, the origin of that practice from the Sushruta Samhita cannot be overlooked, and often the underlying mechanism of the surgery is the same but more sophisticated instruments and drugs are available now for the procedure. Surgery has benefitted from texts such as these which deal with pressing medical conditions such as wounds and amputations that were much more commonplace in ancient and medieval societies [12-14]. As we look at surgery in the present day we can see a trend towards gradually less invasive and more accurate procedures with faster recovery times and lower risks of harm. The Sushruta Samhita exemplifies this trend as it moved away from the pre-historic and primitive practices of surgery and allowed a codified set of rules for surgery to be presented which made the overall experience for the patient safer. The use of specific named surgical instruments and proper training for surgeons is a precursor to the rigorous training doctors must undergo in current training to ensure an adequate standard of care. With the increased possible use of Robot-Assisted surgery and Artificial intelligence in surgical practice there is an argument that many of the practices and basic skills set out in the Sushruta Samhita will become obsolete due to the reliance on less error-prone technologies. Whilst the procedural areas of the text may not be completely relevant, the basic competencies of a doctor will still be necessary in terms of sound medical and surgical knowledge to be used alongside the increased technological innovations taking place.

\section{References}

1. Saroshe S (2016) Sushruta: the ancient Indian Surgeon. Hektoen International: A Journal of Medical Humanities.

2. Saraf S (2006) Sushruta: Rhinoplasty in 600 B.C. The Internet Journal of Plastic Surgery 3: 1-4.

3. Correa BJ, Weathers WM, Wolfswinkel EM, Thornton JF (2013) The forehead flap: the gold standard of nasal soft tissue reconstruction. Semin Plast Surg 27: 96-103.

4. Saraf S, Parihar R (2006) Sushruta: The first Plastic Surgeon in 600 B.C. The Internet Journal of Plastic Surgery 4: 1-7.

5. Raju VK (2003) Susruta of ancient India. Indian J Ophthalmol 5: 119122.

6. Bhishagratna K (1963) An English Translation of the Sushruta Samhita: Sutra-sthāna. $2^{\text {nd }}$ edition, Chowkhamba Sanskrit Series Office, the University of Michigan, USA.

7. Natarajan K (2008) Surgical instruments and endoscopes of Susruta, the sage surgeon of ancient India. Indian J Surg 70: 219-223.

8. Singh V (2017) Sushruta: The father of surgery. Natl J Maxillofac Surg 8: $1-3$.

9. Bhattacharya S (2009) Sushrutha-our proud heritage. Indian J Plast Surg 42: 223-225.

10. Tewari M, Shukla HS (2005) Sushruta: 'The Father of Indian Surgery'. Indian J Surg 67: 229-230.

11. Mark JJ (2018) Sushruta. Ancient History Encyclopedia.

12. Puthumana PP (2009) Through the mists of time: Sushrutha, an enigma revisited. Indian J Plast Surg 42: 219-223.

13. Das S (2007) Urology in ancient India. Indian J Urol 23:2-5.

14. Selin H (2013) Encyclopaedia of the History of Science, Technology, and Medicine in Non-Western Cultures. Springer Science \& Business Media. 